\title{
EchoGéo
}

48 | 2019

Illegal cannabis cultivation in the world

\section{Illegal cannabis cultivation in the world, and as a subject in academic research}

Introduction

Pierre-Arnaud Chouvy

\section{OpenEdition}

\section{Journals}

Electronic version

URL: https://journals.openedition.org/echogeo/17556

DOI: $10.4000 /$ echogeo. 17556

ISSN: 1963-1197

Publisher

Pôle de recherche pour l'organisation et la diffusion de l'information géographique (CNRS UMR 8586)

Electronic reference

Pierre-Arnaud Chouvy, "Illegal cannabis cultivation in the world, and as a subject in academic research", EchoGéo [Online], 48 | 2019, Online since 13 July 2019, connection on 01 August 2021. URL: http://journals.openedition.org/echogeo/17556 ; DOl: https://doi.org/10.4000/echogeo.17556

This text was automatically generated on 1 August 2021.

EchoGéo est mis à disposition selon les termes de la licence Creative Commons Attribution - Pas d'Utilisation Commerciale - Pas de Modification 4.0 International (CC BY-NC-ND) 


\title{
Illegal cannabis cultivation in the world, and as a subject in academic research
}

\author{
Introduction
}

Pierre-Arnaud Chouvy

1 Illegal cannabis cultivation as a worldwide phenomenon is the theme of this edition of ÉchoGéo. As expected, putting together a special issue on illegal cannabis cultivation in the world is challenging since very few scholars conduct on-location research on cultivation specifically and also because very few authors have in-depth knowledge of the plant's history, botany, agronomy, or even industry. This is, of course, because most of the world's drug cannabis has long been and is still cultivated illegally and because illegality has clearly hindered research on cannabis in most producing countries.

2 Therefore, while the authors who contributed to this edition have conducted very valuable research on a variety of countries and regions (by order of appearance: the world, the African continent, the Democratic Republic of Congo, Lesotho, Afghanistan, the United States of America, Europe) and sometimes specifically on cannabis, it proved impossible to find contributors who could write empirically about some of the most notable producing countries in terms of historical importance or quantities produced.

3 As a result, Latin America could not be covered at all, despite, for example, the historical and current importance of Mexico in large-scale commercial cannabis production. Also, no field-based research seems to exist about illegal cannabis cultivation in some other countries with long cannabis-related traditions and with large cannabis cultivation areas and productions, such as India, Nepal, and Jamaica. What is even more surprising, considering their regional and global importance in terms of production, is that neither India nor Lebanon are mentioned among the major producing countries in the 2006 "Review of the world cannabis situation" published by the United Nations in its Bulletin on Narcotics (Legget, 2006, p. 35). Maybe this explains that. 


\section{About academic research on illegal cannabis cultivation}

4 Of course, empiric research - i.e. on-location research based on direct or indirect observation or experience - on illegal drug crops is often difficult to carry: indeed, illegal drug crops are often "dangerous harvests" (Steinberg et al., 2004) that deter many academic researchers from doing fieldwork on that topic. This is even more so the case when illegal crops are grown in war-torn or violence-affected countries, as is often the case (such as in Afghanistan, Burma, Colombia, and Mexico). In fact, the vast majority of the researchers who work on illegal cannabis cultivation focus on case studies located in the Global North. Very few of them carry fieldwork in the Global South, despite the fact that this is where most of the marihuana (herbal cannabis) and clearly most of the hashish (cannabis resin) are produced.

5 This was exemplified in the important 2011 collective book World Wide Weed that focused on "global trends of cannabis cultivation" and "the spread and diversity of cannabis cultivation worldwide" but whose authors dedicated only two out of sixteen chapters (mostly written by criminologists) to southern countries (English-speaking Caribbean and Morocco) (Decorte et al., 2011). This book and the majority of the recent research conducted on illegal cannabis cultivation in the world show how field-based research is limited both geographically (Global North largely overrepresented) and methodologically (predominance of police data, online surveys, with limited onlocation direct observations of the ethnographic, geographic, or agronomic type) (Legget, 2006, p. 61-93) ${ }^{1}$. In comparison, when Cannabis and Culture was published in 1975 as the first collective book on cannabis in the world, most of its articles (written mostly by psychiatrists and anthropologists, as well as by a few botanists) were about countries from the Global South and most of them were based on fieldwork (Rubin, 1975).

6 Surprisingly, not one geographer contributed to either book. In fact, very few geographers have researched illegal drug crops and even fewer have specialised on drug crops in the long-term. Yet illegal drug crop cultivation is a highly geographical issue since it is, as any other agricultural activity, a spatial phenomenon with obvious territorial dimensions. To be fair, very little field-based work has been done in any academic discipline on illegal cannabis cultivation. And fieldwork-based research on other illegal drug crops is also rare, as stressed about opium poppy cultivation by David Mansfield (2016, p. 45). Moreover, coca and opium by-products have attracted a lot more attention than cannabis by-products, even though cannabis is clearly the world's most widely cultivated and consumed illegal drug (Legget, 2006). But the knowledge deficit on cannabis is far from being limited to geography: indeed, as Ted Legget wrote in his 2006 review of the world cannabis situation, "Cannabis is the world's most widely cultivated and consumed illicit drug, but there remain major gaps in our understanding of global cannabis markets" (Legget, 2006, p. 1).

7 In fact, most books on cannabis, such as those by Booth (2003), a historically-oriented author, Mills (2003), a historian, and Duvall (2014), a geographer, have mostly focused on the broad history of cannabis and as such are not derived from primary field-based research in cannabis growing areas. The recent near-encyclopaedic work produced by botanists Clarke and Merlin (2013) on the natural origins, early evolution, and ethnobotany of the cannabis plant, falls between history, botany, and an ethnographic 
study, and consists primarily of a comprehensive critical review of the cannabis-related literature, although with some high-value primary data collection at source over long periods of time. Clarke's precedent book on hashish (1998) is undoubtedly one of the most thorough - yet non-academic - texts on both cannabis and hashish as it offers a rare history of the plant and of one of its main end products (hashish) at various scales (global, regional, and national) but also of cultivation and production techniques in all of the former and present-day producing countries (Afghanistan, Greece, India, Lebanon, Morocco, Nepal, Pakistan, Turkey, etc.) (Clarke, 1998).

academic research in cannabis producing countries in the Global South has most often been limited in time, scope, and depth, there has been some respite over the last decade with the field-based research of Kepe (2003) on South Africa, Afsahi, Chouvy, and Macfarlane in Morocco (Chouvy 2008; Chouvy and Afsahi 2014; Chouvy 2016; Chouvy and Macfarlane 2018), Bloomer (2009) in Lesotho, Botoeva (2014) in Kyrgyzstan, and Laudati (2016) in the Democratic Republic of Congo. Still, as a whole, primary research on illegal cannabis cultivation in the Global South remains extremely scarce and very little is known about who produces what in Afghanistan, Albania, India, Lebanon, or Mexico. This is despite the important role that these countries play as suppliers to regional markets worldwide.

9 The contributing authors to this special issue on illegal cannabis cultivation are amongst the very few who either focus specifically on cannabis production in a given geographic area or include cannabis-related issues in their broader studies of various countries. In other words, and as previously explained by Duvall, cannabis specialists are rare and as a consequence the plant and its agriculture is not always what the authors specifically focus on.

\section{A few case studies, from Africa, Asia, North America, and Europe}

10 This issue opens with a text on the heritages, trends, and challenges of illegal cannabis production in the world in which I first stress how the limited data available about cannabis cultivation is most often inaccurate, unreliable, and highly controversial, and how this has become even more acute of an issue now that global trends towards decriminalisation and legalisation are provoking negative unintended consequences in poor producing countries. The article is an effort to clarify some key notions of the cannabis plant and industry in the context of the geohistory of modern cannabis production from the 1960s on. Overall, the article presents the state of the current knowledge and the present and future stakes of the fast-changing cannabis industry and legislation.

11 The second article, authored by geographer Chris Duvall, focuses on the African continent and its four historical phases of cannabis cultivation, from the plant's initial dispersal across the continent and how pre-colonial agriculture turned African cannabis into a valuable crop, to the development of formal markets for cannabis under colonial regimes, to how prohibition during the twentieth-century affected the economy and political ecology of cannabis production and has weakened the global market positions of African countries, and finally to how the undergoing legalisation processes that are multiplying across the continent largely amount to "instances of 
accumulation through dispossession by Global Northern companies, enabled through the exercise of neocolonial power".

12 Africa, a continent that is usually left out of drug production studies, is the focus of two other articles. Based on years on fieldwork, geographer Julian Bloomer addresses both historical and contemporary developments surrounding cannabis cultivation in Lesotho, southern Africa, with a particular emphasis on rural livelihoods and the impact of illegal cultivation and trade on local and national governance. He shares some of Duvall's concerns when he critiques some of the developmentalist rhetoric surrounding the granting of licenses for medical cannabis put forward by investors now that Lesotho has become (in 2017) the first African country to license cannabis production for medical and scientific purposes, although to the advantage of wealthy bio-prospectors rather than to the rural poor.

The other African case study is that of the Democratic Republic of the Congo where geographer Ann Laudati has conducted extensive fieldwork with those engaged in the cannabis production and trade in the context of war. In her paper she challenges the narrative of violence, delinquency, and greed that overwhelmingly foregrounds most discussions of Congo's cannabis economy. By doing so she shows how the cannabis trade has become a response to Congo's insecurity and violence, rather than a symptom of it, and how inaccurate it is to reduce the cannabis industry to a vehicle for violence, underdevelopment and regional instability.

14 After three articles on Africa, this issue of ÉchoGéo features a text on Afghanistan, the only Asian country for which authors capable or willing to write about cannabis cultivation could be found. Of course, cannabis having originated and evolved in Asia before it spread to the rest of the world, the near-complete absence of cannabis specialists in/of Asia is a blatant proof of the "truly glaring gap on cannabis production, distribution, and consumption" that exists in the academic literature on cannabis (Taylor et al., 2013, p. 425-426).

15 Historian James Bradford and development and rural livelihood specialist David Mansfield joined forces to produce an article on cannabis cultivation in Afghanistan, a country that "is believed to have one of the oldest continuous cannabis cultures in the world". Afghanistan is also famous the world over for his high-quality hashish and because of its cannabis landraces (and names) and the role they played in the hybridisation of cannabis strains in the United States and the Netherlands in the 1970s. An article on cannabis in Afghanistan was all the most important also because, since the 1980s, the narrative of drugs in Afghanistan has been overwhelmingly defined by opium, of which the country is the world's first illegal producer. However, as explained by the authors in both historic and economic terms, cannabis production has remained an enduring component of Afghanistan's political economy and culture and has most recently evolved in response to local, regional, and global factors.

16 After covering limited parts of the Global South, this ÉchoGéo issues dedicates two articles to the two main producing areas of the Global North, starting with a text by historian Nick Johnson on the United States of America. Johnson offers a refreshing history of the illegal cultivation of cannabis by mapping out the driving social, economic, geographic, and environmental forces of illegal (and in some cases, legal) cannabis cultivation in three parts of the United States: Midwest, South, and West. This is all the more meaningful since the United States has long played a leading role in the development of the modern cannabis industry (seed breeding, indoor cultivation 
techniques, etc.) worldwide and has been one of the premier cannabis-growing regions of the world since the 1960s.

The situation is different in Europe, as reminded by sociologist David Weinberger, drug studies specialist Michel Gandilhon, epidemiologist Jalpa Shah, and economist Nacer Lalam. While Europe has also played a leading role in the development of the modern cannabis industry (seed breeding, coffee shops, grow shops, cannabis cups, etc.), it has never reached the production level attained in the United States, or in California alone. Yet, as explained by the authors, illegal cannabis production has been increasing rapidly during the past decade, whether indoors or outdoors, from the United Kingdom in the West to Albania in the East and to Spain in the South (where the seed breeding business now rivals that of the Netherlands). Highly potent marihuana is now produced in very increasing quantities in Europe, notably by criminal groups, and now competes with a Moroccan hashish that has long been the first cannabis endproduct consumed in various European countries.

In the last article I resort to an overarching comparative approach to show how various degrees of politico-territorial control or law-enforcement deficit by the state can explain, to some extent, the existence of large expanses of illegal drug crop cultivation. Based on the empiric case studies of Morocco, Afghanistan, northeast India, Burma/ Myanmar, and the United States of America, and on both cannabis and opium poppy illegal cultivation, I describe how large-scale illegal drug crop cultivation can take place according to three main scenarios: that of a full-fledged but inefficient war on drugs; that of toleration, for various motives, of illegal drug plant cultivation by the state (which can amount to negotiated but effective control); and that of the militarilychallenged state that cannot exert full control over its territory. I conclude that, since total politico-territorial control is clearly impossible, neither drug production and trafficking, nor drug consumption are achievable goals. Between total repression, state toleration, corruption, and even the abandonment of a costly and ineffective war on drugs, the states and the societies involved in the drug industry end up drawing an ever-revised map of illegality that implies that prohibition and the war on drugs are lost causes.

\section{Towards a new cannabis era, and hopefully further research.}

While this ÉchoGéo issue offers new material on cannabis cultivation in various countries and regions of the world, it also reveals how many blanks exist in our knowledge map and how much more research is needed to fill these gaps. As explained earlier, the problems of illegality and insecurity have led to a knowledge deficit that is apparent in the existing body of literature on cannabis, this ÉchoGéo issue included. The majority of this literature is the work of historians, sociologists, criminologists, and largely focuses on consumption, not cultivation, in the Global North more than in the Global South. In terms of research methodology there is an over-reliance on official data such as police records and interviews, and online surveys with few, if any, onlocation direct observations of an ethnographic or geographic nature.

This is why further research is needed, notably by geographers, anthropologists, agronomists, etc., to address an urgent knowledge and policy gap about cannabis 
cultivation in the main producing countries. This is all the more important since official data on levels of cannabis cultivation is particularly unreliable. But sometimes official data and general knowledge also suffer from a simple observation deficit (from academics, journalists, etc.) as was the case in Morocco when there was a failure to acknowledge that any reductions in cultivation that had taken place in the country had been more than offset by increased yields and potency made possible by improved cannabis varieties and more efficient agricultural techniques (Chouvy and Afsahi 2014).

More specifically, there is a paucity of empirical research at the world level on cannabis farmers and their communities in most producing countries. There are few insights for example with regard to: the role that cannabis plays in the livelihoods of rural populations and the importance of the crop to their local economies; evidence of new cultivation and production practices and technologies and how these impact both on local political-economies and the long term sustainability of production and their environmental bases; and how local farmers in producing countries interact and work with the growing cannabis economy in the United States and Europe. Most importantly, the lack of research on cannabis means that there is very limited understanding about how the existing national cannabis markets will adapt and evolve both in the Global North and in the Global South depending notably on ongoing and forthcoming legislative changes (decriminalisation or legalisation).

Much of the policy debate on changes in the legislation in the Global North focuses on the impact that the decriminalisation or legalisation of cannabis might have on its own societies and economies. But there is little to no discussion on how changes in cannabis legislation in the Global North might impact on the socio-economic and political conditions in producing countries of the Global South where cannabis growing communities will suffer from economic contraction. It was one of the goals of this ÉchoGéo issue on cannabis in the world to draw attention to such questions and issues.

Indeed, the future of the world's varied cannabis industries is very uncertain as the ongoing farming and legislative changes are going to affect the way the global, regional and national markets have been structured during decades. New North-South, but also North-North and South-South dynamics are about to emerge as some countries and some states have legalised recreational and/or medical cannabis. Also, the recent adoption of modern high-yielding varieties and farming techniques (modernisation of cannabis cultivation and modernisation of cannabis by-products' production) will necessarily impact the global map of cannabis cultivation, with economic (further impoverishment of some of the resource-poor cannabis farmers), socio-political (unrest, contestation, repression, etc.), and environmental (water depletion, soil exhaustion, loss of landraces, etc.) consequences that must not be ignored. 


\section{BIBLIOGRAPHY}

Bloomer J., 2009. Using a political ecology framework to examine extra-legal livelihood strategies: A Lesotho-based case study of cultivation of and trade in cannabis. Journal of Political Ecology, vol. 16, n 1, p. 49-69.

Booth M., 2003. Cannabis. A History. London, Doubleday.

Botoeva G., 2014. Hashish as cash in a post-Soviet Kyrgyz village. International Journal of Drug Policy, vol. 25, n 6, p. 1227-1234.

Chouvy P.-A., 2008. Production de cannabis et de haschich au Maroc : contexte et enjeux. L'espace politique, $\mathrm{n}^{\circ}$ 4, p. 5-19.

Chouvy P.-A., 2016. The Supply of Hashish to Europe. Background paper commissioned by the EMCDDA for the 2016 EU Drug Markets Report, European Monitoring Centre for Drugs and Drug Addiction, Lisbon: EMCDDA, April 2016.

Chouvy P.-A., Afsahi K., 2014. Hashish Revival in Morocco. International Journal of Drug Policy, vol. $25, n^{\circ} 3$, p. 416-423.

Chouvy P.-A., Macfarlane J., 2018. Agricultural Innovations in Morocco's Cannabis Industry. International Journal of Drug Policy, vol. 58, p. 85-91.

Clarke R.C., 1998. Hashish! Los Angeles, Red Eye Press.

Clarke R.C., Merlin, M. D., 2013. Cannabis: Evolution and Ethnobotany. Los Angeles and Berkeley: University of California Press.

Decorte T., Potter G.R., Bouchard M., 2011. World Wide Weed: Global Trends in Cannabis Cultivation and its Control. Farnham, Ashgate Publishing.

Decorte T., Potter G.R., Bouchard M., 2011. The Globalization of Cannabis Cultivation. In Decorte T., Potter G.R., Bouchard M., 2011. World Wide Weed: Global Trends in Cannabis Cultivation and its Control. Farnham, Ashgate Publishing, p. 1-22.

Kepe T., 2003. Cannabis sativa and rural livelihoods in South Africa: politics of cultivation, trade and value in Pondoland. Development Southern Africa, vol. 20, n 5, p. 605-615.

Laudati A., 2016. Securing (in)security: relinking violence and the trade in cannabis sativa in eastern Democratic Republic of Congo. Review of African Political Economy, vol. 43, $n^{\circ} 148$, p. 190-205.

Legget T., 2006. Review of the world cannabis situation. Bulletin on Narcotics, vol. LVIII, $\mathrm{n}^{\circ} 1$ and 2 . Mills J.H., 2003. Cannabis Britannica. Empire, Trade, and Prohibition 1800-1928. New York, Oxford University Press.

Rubin V.R. (ed), 1975. Cannabis and Culture. The Hague \& Paris, Mouton Publishers.

Taylor J.S., Jasparro C., Mattson K., 2013. Geographers and Drugs: A Survey of the Literature. Geographical Review, vol. 103, n 3, p. 415-430. 


\section{NOTES}

1. Recent trends in academic research on illegal cannabis production, trade, and consumption are mostly set by historians and criminologists: see the Cannabis Global Histories conference that took place at the Strathclyde University in Glasgow (https://www.strath.ac.uk/humanities/ schoolofhumanities/history/cannabisglobalhistories/) and the Global Cannabis Cultivation Research Consortium based in the Netherlands (https://worldwideweed.nl/).

\section{AUTHOR}

\section{PIERRE-ARNAUD CHOUVY}

Pierre-Arnaud Chouvy, pachouvy@geopium.org, is a geographer at the Centre national de la recherche scientifique (CNRS) in Paris, France, UMR 8586 Prodig. He edits www.geopium.org and www.chouvy-geography.com. He recently published:

- Chouvy P.-A., 2018, De la recherche de terrain sur la production agricole illégale de drogue, L'Espace Politique [En ligne], vol. 35, n² 2. http://journals.openedition.org/espacepolitique/5372 - Chouvy P.-A., Macfarlane J., 2018. Agricultural Innovations in Morocco's Cannabis Industry. International Journal of Drug Policy, vol. 58, p. 85-91.

- Chouvy P.-A., 2018. Illegal drug plant cultivation and armed conflicts. Case studies from Asia and Northern Africa. In Zurayk R., Woertz E., Bahn R.A.(ed.), Crisis and Conflict in the Agrarian World: An Evolving Dialectic. Oxon, CABI Publishing, p. 64-72. 